\title{
GAMIFICATION AND RESOURCE POOLING FOR IMPROVING OPERATIONAL EFFICIENCY AND EFFECTIVE MANAGEMENT OF HUMAN RESOURCES: A CASE STUDY WITH AN ECOMMERCE COMPANY
}

\author{
KDV Prasad and Mruthyanjaya Rao M \\ RTM Nagpur University, Nagpur, Maharashtra Ste, India
}

Rajesh Vaidya

Management Technology, Shri Ramdeobaba College of Engineering \& Management, Katol Road, Nagpur, India

\begin{abstract}
The authors of this article attempted combining the two methodologies of gamification and resource pooling with a view to derive the maximum productivity from the organization drawing certain significant commonalities. Another biggest motive behind the authors for combining these two techniques is the fact that eCommerce is a business vertical or a market place where people from all walks of life participate in online purchases. eCommerce is not a market place where it is restricted to one particular community, region, age, colour etc., So to interact, involve and conduct the business operations with an inclusive mindset, the authors thought that it would be appropriate to gamify and pooling the resources such that there would be a perfect blend of resources with utmost motivation to serve all the stakeholders, irrespective of their age, gender, community, region, economic status, in ecommerce. It turned out to be a practical solution as it proved to be promoting an atmosphere that fosters friendship and loyalty, and these close-knit relationships motivate employees; align them to work much harder, cooperate and be supportive to each other. This is possible because every individual possesses diverse talents, weaknesses, communication skills, strengths, habits, and hence it is optimally balanced out.

Gamification is a method to enhance employee engagement, behavioral change and motivation. Application of gamification is not limited to eCommerce business models, but can be applied to various other business models in the sectors like education, research, healthcare etc. So also, the human resource pooling is building and grouping of human resources for best use to improve the operational efficiency and reduce the costs. The human resource pooling can happen during fine tuning of a cultural fit, organization mergers, change in organization structure, technological changes and on acquiring new technology. In this study we have considered a group of 120 employees who were further divided to 6 functional groups, having 20 employees in each functional
\end{abstract}


group. In this paper we report the outcome of application of gamification and resource pooling techniques and benefits in an eCommerce industry.

Keywords: Gamification, resource pooling, motivation, behavioural change, employees

Cite this Article: KDV Prasad, Mruthyanjaya Rao M and Rajesh Vaidya, Gamification and Resource Pooling for Improving Operational Efficiency and Effective Management of Human Resources: A Case Study with an Ecommerce Company, International Journal of Management (IJM), 10 (6), 2019, pp. 76-87.

$\mathrm{http}: / /$ iaeme.com/Home/issue/IJM?Volume $=10 \&$ Issue $=6$

\section{INTRODUCTION}

\subsection{Gamification}

The theory and perception of gamification and its methods in non-gaming contexts are fast evolving practice in the business world. Gamification is the use of game components, game design thinking in non-gaming contexts and its originated from computer-based game business. The term gamification was coined by Nick Pelling in 2002 [1], however only in the recent past several industry embraced the gamification. The game thinking and application of game mechanics in non-gaming environment to find solutions to problems related to any business including education, healthcare, marketing, websites and to create a positive impact on behavior. Application of gamification in business or research context by integrating game dimensions to promote the engagement of audience - customers, students, teachers, researchers using in website, research services, online portals and strategic market campaigns. The gamification methods influence persons' natural needs to compete, achieve, get recognition and self-expression. Several Information Technology companies introduced the said concepts to make work-life balance, changing in behavior and increase motivation.

The three components the gamification mechanism uses are badges, points and leader boards. Several studies reported the employees who received or awarded badges based on their performance responded proactively and in turn improved at work-place environment and increased performance. Gartner [2] reported that several organizations embracing gaming mechanisms and rewards to motivate employees and customers. Gamification is rapidly making evolution in several mainstream industries, to enhance employee engagement and motivate employees. The latest know-how and technologies via hand-held devices like mobile phones, tabs, enhancing the application of gamification in work-life. The gamification though a buzz word is still in a nascent phase, the gamification methodologies found to be easily applied. Yusuf et. al. [3] reported the benefits of application of gamification on sales-force performance in Nigerian bottle company applying games mechanics points and rewards. Gamification is a planned procedure for enhancing the employee performance using gaming elements in nongaming environment. The gamification is pretty new almost all the latest gamification methods over emphasizing the game elements, and this is a wrong concept in related to address psychological issues [4]. For a successful gamification in any organization the behavior of an individual is his/her cultural aspects needs to be assessed thoroughly.

Hanus and Fox [5] suggested the identification of what exactly need to be gamified for getting beneficial effects of non-gaming context and psychological and social that trigger serious game play in the business environment are important aspects that need to be considered. Most of the employees and customers expect rewards and participating certain activities rather than for their actual achievement [6]. Most of the Millennials believe in team tasks, however most of the team members' commitment is low and need behavioral changes [7]. The gamification mechanism where the industry is using at present mostly include points, 
promotions, discounts, rewards and level advancement and some game elements to motive and inspire the people [8]. The gamification is beneficial for workforce engagement in enhancing performance, increased skills, change in their behavior and adopt for changes in the volatile business environment [9]. Hew et al. [10] proposed rewards, points, badges, level achievements, and trophies.

\subsection{Resource Pooling}

The assembling of human resources, infrastructure, assets, machines etc. is resource pooling to drive the optimal advantage from the pools which are gathered in group [11] To maximize the benefits and minimize risk the resource pooling can be helpful. The Human Resources Pooling is a method to combine a mix of different employees or people from different backgrounds, knowledge base with diversified skills to descend maximum benefit and increase the productivity at optimal level. Resource pooling is a cost effective method to deliver best possible from the employees under several financial constraints. Mruthyanjaya Rao et.al. [11] reported significant benefits from the resource pooling in a study on eCommernce industry in and around Hyderabad.

The resource pools will have various set of skilled employees there is a possibility that high quality work and output can be realised. The pools will have multi-culture people with varied backgrounds, languages, cultures which create a huge knowledgebase. The diversified skill sets helps in managing the organization during merging and clusters where the redeployment is smooth and easy. The resource pool is a group of individuals who can take new challenges that includes a pool of talent from diverse backgrounds, multi-skills and varied experiences. This group consists of full time employers, part timers and even freelancers [12].

Resource pool enhances the supply of resources in a meaningful way to optimize human resource planning and business operations. The organizational needs and volatile business environment sometimes forces to pool the available resources, with the help of HR department. Though the polling of resources entirely depends on the type of organisation, and its vision and mission some static and new pools can be added in some cases. The staff who are on workbench is a type of resource pooling techniques for redeployment of human resources in near future [13].

\section{REVIEW OF LITERATURE}

\subsection{Gamification}

The badges, points and leaderboards are the main elements of the gamification which includes competition with some game rules, with choices, autonomy, and these elements are used in decision making and to find solutions for in business environment [14] Gamification is widely used in learning and development including serious game elements. The LinkedIn profile progress bar motivates the use to complete the profiles providing full information. The main aspect of gamification is the motivation and behavioural change of the players who are human beings. Most of the gamification players will earn badges, point, face new challenges and moving level by level in game like environment. Some business houses Nike and Amazon gamified their business website award points which can be deemed for customer reviews and product recommendations. Certain badges also displayed adjacent to the customers review showing the points earned. For Foursquare, the sharing of their location with the colleagues and friends is an important aspect. The users will be rewarded with the values on social network on sharing their location, Foursquare motivates the users with badges when they check in the some certain places.

The gamification will motivate and help the business houses to improve their businesscritical operations. The internal gamification, external gamification and behavioural change 
gamifications are important aspects suggested by Kevin Werbach and Dan Hunter [15]. The authors also suggested game elements smaller pieces and are embedded into activities, game design techniques is a science can be used to enhance the business operations, and non-game contexts which involve real world business and societal goals. The three main reasons for gamifying the business is Engagement, Experimentation and Results, where engagement if the gamification is well designed will be meaning full and challenging to the employees [15]. Experimentation is necessary to have game-based motivation which can be used in business envirionments non-game context. If gamification works, which is entirely depend on the game design will produce the good results. Apart from the points, badges and leaderboards the other three categories of game elements dynamics, mechanics components are important to gamification. The components are the specific instantiation of mechanics and dynamics, where mechanics are basic processes that motivate for player engagement. Aberdeen Group ([16] reported that several organizations benefitted from use the gamification with enhanced performance, optimal engagement and retention. Penny Simpson and Pete Jenkins [17] reported the gamification and its use in human resources such as attracting the talent, induction, engaging, retaining, learning and development.

Gamification can be used for enhancing employee productivity, behavioural change, learning and education, loyalty [18]. In the recent past there is considerable awareness and potential use of gamification in human resources mainly in the areas of training and development and modern learning techniques [19, 20]. The Association of Project Managers (APM) study applied gamification methodology to some behavior models like Maslow's Hierarchy of Needs and reported that gamification can be used to three levels of the Hierarchy. Pink [21] in his study reported a correlation between basic idioms of gamification and hierarchy of needs and the deficiency needs in the model positively appraised the application of gamification, where people can reach to certain status, reputation and social cohesion. Bunchball [22] explained the behavioural changes on a player who paly monopoly on routines basis and on addition of elements like levels, statistics will change behaviour and the player is more inclined towards the game without boredom. The author suggested team rewards on attaining the tasks, badges for individuals for recognition. Kaananen and Akpinar [23] reported the cost savings using gamification for motivation of salesforce using an interview method. An empirical study using gamification and social networking indicated an average response with both the elements when used for e-Learning methodology in computer education [24]. Richard et al. [25] used gamification with leaderboards and reported that most of the participants fall the best category and easy goal setting environments and this study was conducted applying goal setting theory with random selection of the participants. To conclude gamification can be effectively used in structure of the workforce due to generational shift as some proactive industry preparing for new generational demands for including the process of gamification [26]

\subsection{Resource Pooling}

Mruthyanjaya Rao et al. [11] reported cost savings, less employee slack times, efficient use of human resources in their study on a IT conglomerate optimizing the human resources and resource pools. Resource pooling also incur costs and create difficulties at starting stages and some employees will resist the change and the employees reporting and departmental structure will be difficult to create during the initial stages. The reporting mechanisms and structure will be difficult in the initial period and will resisted by some employees reducing the performance temporarily, however it is better opportunity to make better use of available resources [27]. For better management of the organizations and the resources and also to improve the quality of work, the pooling of human resources is essential 
Proactive management of the resource pools and team work among the pooled groups is needed to realize the benefits at optimal level. There are several technics and tools are available to develop cohesiveness, greater flexibility and for efficient management of pooled networks[28]. Msiska [29], Reported the effective and efficient implementation and restructuring of DHIS2 health information software platform in Malawi. The author also assessed the efficiency challenges and factors for staff pooling as a strategy to mitigate resource pool slack times in developing countries. The resource pooling can be used in assessing the Diversity and inclusiveness in an organization.

Talent Pooling can be done based on the type of business and roles where flexibility and team work is critical [30]. The assumptions on recruitment strategies with wide range of diversity can be possible with resource pools. Some big enterprises are under resource pool audits for valuing, to estimate the cost-benefits, and under certain circumstances pooling of accounting may not be allowed. For preparing for business combinations and forecasted advantages, the professionals need to review their plans and this will take several iterations in an organisation and future planning and the costs incurred are critical [31]. In general resource pooling is done across the organisations on based on similar job assignments and job roles.

\section{THEORETICAL FRAMEWORK}

The theoretical framework for this study is based on the model provided by Yusuff et. al. (2019) and little modified version of six Ds Define research objectives, Delineate the employee target behaviors, Describe employees, Devise activities start and end, Don't forget the fun and Deploy require tools and resources based on the model suggested by Kevin Werbach and Dan Hunter (2015).

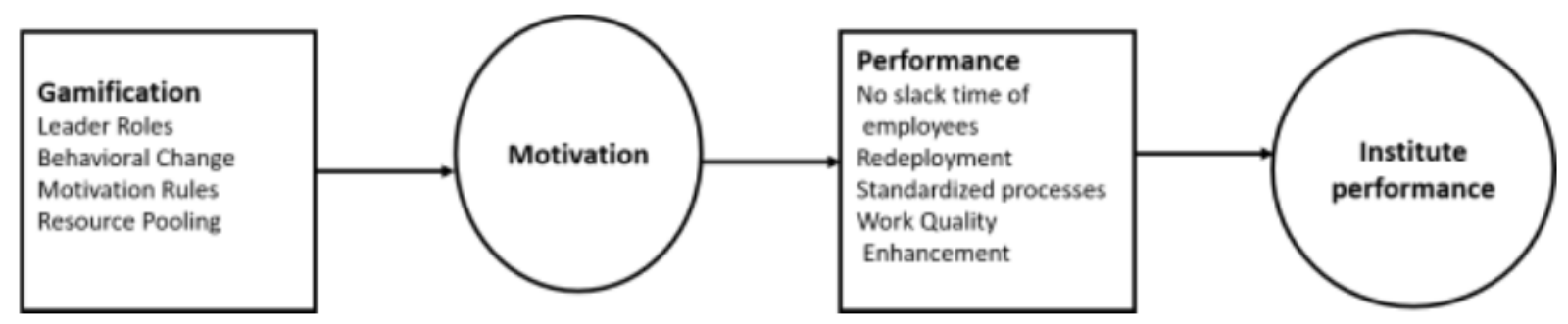

Figure 1. Gamification with resource pooling a theoretical framework

\subsection{Resource pooling}

During our research analysis we have observed the similarities in several functions across the organisation in different departments and we proposed to pool the human resources of the departments i) Service Delivery: takes cares of project delivery on time. ii) Business Operations: ensures operations safety, and smooth operations iii) Sales \& Support: Pre sales and post sales services iv) Marketing \& Communication: Ensure efficient marketing of product deliverables with minimum advertisement resources. v) HR \& Admin: Routine human resources and administrative responsibilities vi) Finance \& Accounts: Financial and accounting aspects of the organization.

Figure 2, the present hierarchical structure organization type hierarchy, with further divisions towards the downward and other functions Software development and testing, Integration, and their Units (not shown in the Figure 2) has with too many levels is difficult to handle and all and staff with similar functions working in isolation separately which not cost effective. From the present structure there is every possibility of slack time of employees and under-utilization of human resources. Therefore, resource pooling was planned with new structure as indicated in Figure 2. 


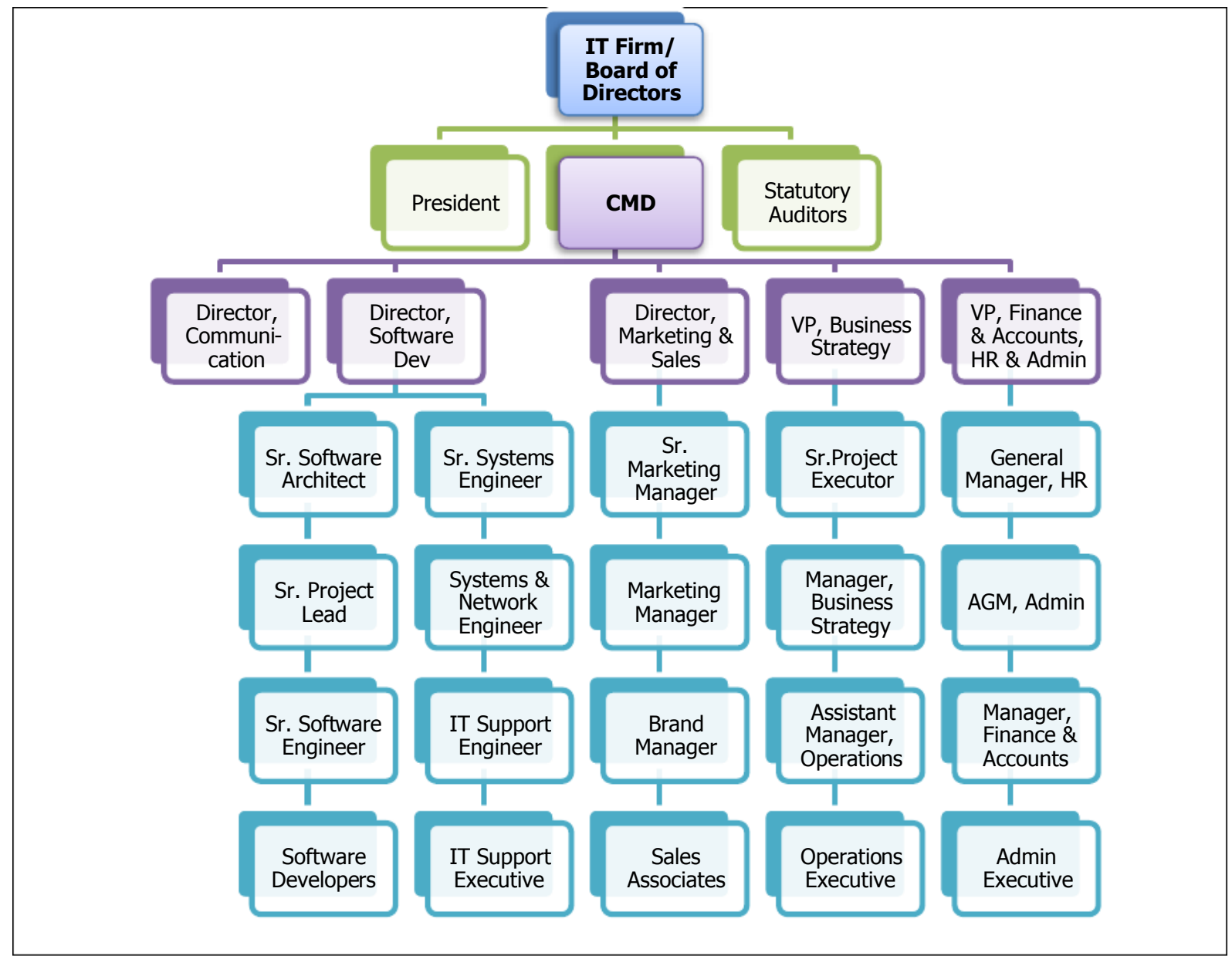

Figure 2. Organization Hierarchy (Present) - Hierarchical type structure

Considering carefully each of the function and staff some positons across the functional groups can be pooled based on the common job responsibilities. This will reduce the supervision and increase the efficiency through gamification. The staff carrying out common job roles in HR payroll, and Admin and Finance are pooled which can carry salary processing and bills scrutiny.

The new developed structure have six functions in total where the resources are pooled with common job roles and pooled and brought under one reporting level SBIO Head. 
Gamification and Resource Pooling for Improving Operational Efficiency and Effective Management of Human Resources: A Case Study with an Ecommerce Company

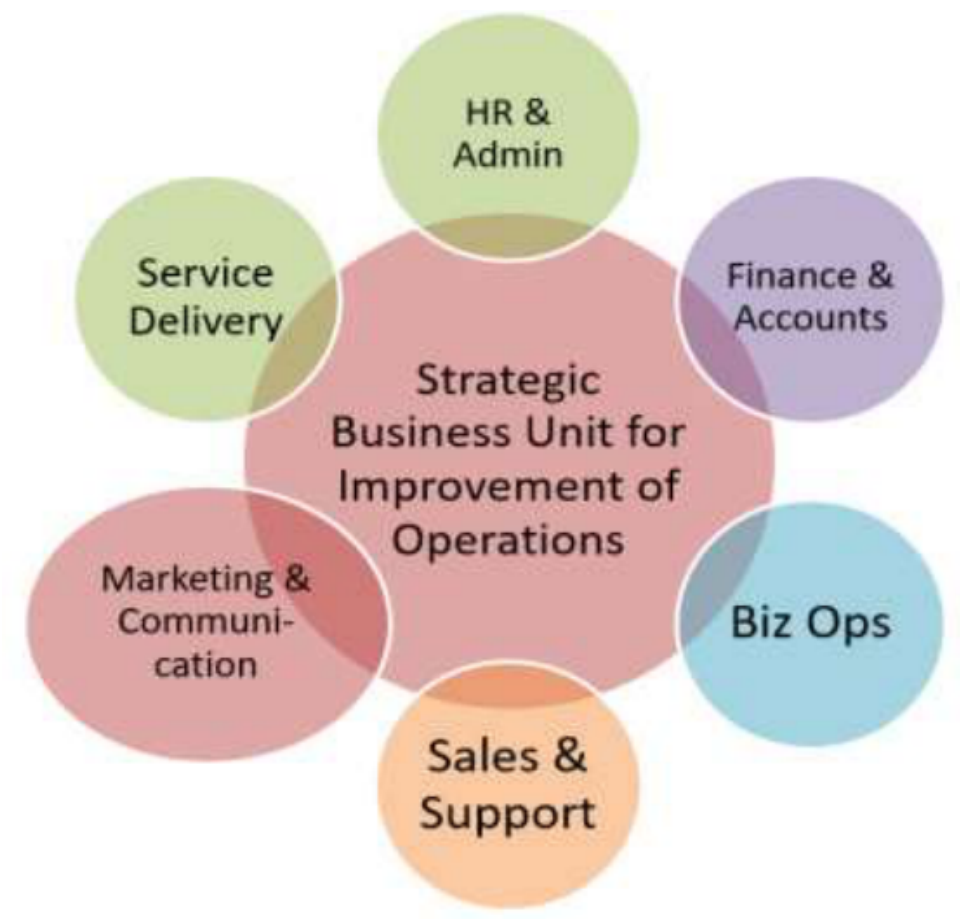

Figure 3. Proposed new structure with resource pooling. The SBUIO shows both overlapping relationships and the relationship of a central idea in a cycle. Every function outside corresponds and combined to make the unit efficient and multi-tasking unit.

The old structure (figure 2) is slow and expensive where as new structure (figure 3) will improve quality, enhance team work quick, saves resources.

\subsection{Gamification}

\subsubsection{Define Objectives}

- By removing the responsibility of operational and logistical execution of all routine activities from individual heads, so the heads can focus on strategic business activities, standardizing methodologies, strategies critical to business

- To standardize of processes, focus on methods, effectives of activities and delivery of results

- To provide greater continuity and potential to make it more attractive and efficient talent and offer a career path

- To centralize operations, and develop specialization teams with enhanced skill sets, increase quality and precision in tasks

\subsubsection{Delineate target behaviors}

- Behavioral improvement to improve quality tremendously and saving resources

- Visit competitors web-site for at least 30 min a day

- Share the information across the function units

\subsubsection{Describe and group the employees}

- The employee segmentation was done based on the common functional attributes in each department assigning the similar roles to the group. If any group member is absent that will not effects the job as other group member will do the needful. 


\subsubsection{Devise activity cycles}

- Activity cycles are devised in a linear way with clearly defined beginning and end based on their job roles

Engagement loops

- Provide interesting and challenging job assignments and move the staff across the teams based on the demand so the employees are engaged perfectly

\section{Don't forget the fun}

- A three-day team-building exercise for all the six functional staff in an external venue with the help of content provide who are professional game designers in non-game contexts carried out. The employee games which has challenge and fun are planned to motivate the employees

\section{Deploy appropriate tools0}

- All the tools required to carry out the gamification and resource pooling are deployed.

\section{GAMIFICATION PROCESS}

\subsection{What to Gamify?}

In this research study we have considered to enhance the employee engagement, motivation, behavioral change as the main elements need to be gamified. Keeping in mind that gamification will not offer a complete game experience, we proposed to use same game elements with certain rules to attain specific goals. Our research study concentrated on intrinsic and extrinsic motivation, behavioral change and self-determination theory. Before starting actual gamification a survey questionnaire was circulated among all the group members to capture demographic data, present activities, Favorite subject(s)/activities in current job, Development area subject(s)/professional interests, Professional ambitions/job aspirations: Training required if any (Please mention area of training required); Leisure activities/hobbies/extracurricular interests. The group members also asked to write if they are ready to take the responsibility of group leader/deputy group leader up to 4 levels. After receiving the data the motivational exercise was carried out.

\subsection{Motivational Exercise}

A three-day team building exercise was carried out in a nearby resort which included fun games, some serious games and some official exercises. The employees were explained to do some activities with a message that he/she will be made group leader/deputy leader of the said six groups with a lead facilitator if actively participated in the workshop. This generated motivation in all the employees and leaders and deputy leaders were announced for all six groups. Each leader and deputy leader handling about 10-12 employees and assigned responsibilities. The groups were asked to carry out certain work specific activities and informed the staff if any group complete the activity within stipulated time without effecting the quality they will be rewarded with points. These points can be redeemed later. The employees are motivated intrinsically as they wanted to the activity on their own the this lies inside the activity. The other groups also motivated by extrinsically as they need to compete with other groups. The whole process used three components motivation, action and feedback. The main idea of this exercise is to change the employee behaviour, to share the available knowledge with group members and carry out the job with autonomy.

The points were given for completing certain tasks in specified time. This is for showing an inclination to take the responsibility of lead facilitator, team leader/deputy leader, transforming the knowledge to the colleagues. An environment for continuous feedback was created among 
the groups, goals were set. On reaching the goals employee will be rewarded with points an badges

The groups also developed masteries in dealing with the external environment and developed social connections with their unknown colleagues with esteem relatedness. The assignment of the staff as group leaders and deputy group leaders developed autonomy. This was in line with the Self-determination theory proposed by Edward Deci and Richard Ryan.

\subsection{Behavioral Change}

How good you are in gamification and game thinking design, the success of gamification depends on behavioral change of the employees. Behavior stimulation is required to realize the optimal benefits of gamification. We have followed some behavioral change strategies as given below

Reducing the Group Weights: The group weights of the employees are taken and informed the employees whichever the group reduce their weight $10 \%$ of group weight will be rewarded by points and badges. The group started cycling to the shorter distances $(2-3 \mathrm{kms})$, abandoned four wheelers, and used stair case rather than lift. Starting consuming smart food rather than junk food. This is a behavioral change motivation observed in employees. This exercise created a potential for weight management and employees have changed their eating habits to maintain health.

\subsection{Employee Encouragement through Behavior Change}

Employees were explained about their full potential and huge scope for improvement. Employees were asked to download an app which can be used for their routine job assignment and employees were influenced the behavior of participants using this application with perceived benefits and features. The employees used the application repeatedly and made a habit of doing their assignments with application. From this exercise we could identify employee motives of use of tabs and downloading the and its use. To further motivate the employees, a questionnaire was circulated to know the employee opinions on design and usage, ease of download and installation, simplicity and convenience, customizability of app to suit the job needs

Rewards for motivating the behavioral change: In the said six functional areas several skilled, semi-skilled and unskilled workforce carrying out mundane jobs. The cost of the workforce is an addition to the staff salaries and times becoming critical because of workforce protests for increasing the daily wage cost for the labor. Our primary analysis reveal the staff are requesting more workforce than the required. To make workforce cost savings we proposed a target of 50 per cent cut in workforce requirements by gradually by step by step basis. In addition to this modernization of the six functional areas, wherever possible to reduce the workforce will be carried out. However, to further motivate the staff we also proposed that whichever group cuts the workforce cost, based on the cost savings some portion will be rewarded onetime to the group staff members. Though, this is against the gamification principles, onetime reward will bear effect on the methods.

\section{RESULTS}

The application of gamification techniques improved quality of work as employees are more engaged in work. The staff will be moved between groups based on the seasonal demand and this will facilitate the staff to learn all the functional areas so redeployment of staff is easy without any hindrance to the operations. As the strategic managers are free from routine logistic and operational functions, they can concentrate on standardizing operational methods, processes to improve the effectiveness and delivery of results. The gamification method applied 
provide a greater continuity and potential to make it more attractive, high engagement, and attract good talent and offer a career path. By centralizing the operations specialisations teams are developed with better and improved skillsets and increase quality and precision of tasks. Most of the six functional areas are modernized with online systems, errors will be reduced, operations are transparent with improvement in quality, quick and save resources. The staff are motivated because each team will have primary and secondary team leads, with a Lead facilitator for each group offering cath.

\subsection{Challenges and Opportunities}

\begin{tabular}{|l|l|l|}
\hline \multicolumn{1}{|c|}{ Challenges } & \multicolumn{1}{|c|}{ Opportunities } & \multicolumn{1}{c|}{ How the group can do } \\
\hline Working in new areas & $\begin{array}{l}\text { Chance to learn about other functional } \\
\text { areas, improve skills and more choices }\end{array}$ & $\begin{array}{l}\text { When group finished with the assigned } \\
\text { work in their core functional area they } \\
\text { will be assigned to additional tasks in } \\
\text { other groups. This reduce the employee } \\
\text { slack time }\end{array}$ \\
\hline $\begin{array}{l}\text { Working with new state of art } \\
\text { online system }\end{array}$ & $\begin{array}{l}\text { The online system is user friendly, reduce } \\
\text { errors, quick and reduce losses to viability }\end{array}$ & $\begin{array}{l}\text { Train the group members with new } \\
\text { online system }\end{array}$ \\
\hline $\begin{array}{l}\text { Working as a part of new } \\
\text { group/team }\end{array}$ & $\begin{array}{l}\text { Building new relationships across the } \\
\text { functional areas - Relatedness }\end{array}$ & $\begin{array}{l}\text { Regular group meetings to improve } \\
\text { inter-personal relationships and enhance } \\
\text { motivation }\end{array}$ \\
\hline Managing respective teams & Leadership skills enhancement & $\begin{array}{l}\text { Team building and leadership training } \\
\text { through external content providers, } \\
\text { exposure to visiting similar industries, } \\
\text { team games }\end{array}$ \\
\hline
\end{tabular}

\section{CONLUSIONS}

The implementation of a new system in the study case resource pooling and gamification initially the employees resist for the change. In this study we have made the changes gradually over a year, interacting with the six functional staffs. Held three meetings with the staff why this exercise is needed for long-term sustainability and new structure was explained and feedback received. A three-day team building exercise with the help of content providers were held at an external venue which motivated the employees. Employees were guaranteed that there will be no job loss and resources are moved across the teams based on the employee choice and their interest in the functional areas. The main challenge in this whole implementation is behavioural change and reasonable game design. Several iterations were carried out in the game design before implementation. Though with the initial problems, system was made to near perfect in an year's time with reducing the workforce by 30 percent. Some of the group members need immediate delight, success and recognition at workplace are met by gamification elements creating lead facilitator roles, team lead and deputy team lead roles.

This empirical research gives further confidence to the authors in believing the fact that if these two combination of techniques applied with correct design principles, appropriate player engagement strategies and, most importantly, integrating with social media tools like Facebook, Twitter and WhatsApp using GPS (Global Positioning System), this would have a tremendous impact not only in better purchasing experience in eCommerce, but would add significant value and also it could be much more transformational in other business segments, which one can attempt to conduct future research in this perspective. The authors believe the similar type of methodology can be applied to other business spheres where similar functions exist, and thereby operational efficiency can be improved thereby skills would be improved, innovation would be propelled with changing positive behaviour patterns. 
Gamification and Resource Pooling for Improving Operational Efficiency and Effective Management of Human Resources: A Case Study with an Ecommerce Company

\section{REFERENCES}

[1] Pelling, N. The (short) prehistory of "gamification"... Funding Startups (\& other impossibilities).Availableat:https://nanodome.wordpress.com/2011/08/09/the-shortprehistory-ofgamification/ [Accessed September 16, 2015], 2011

[2] Gartner Research. 'Gartner says more than 50 per cent of organisations that manage innovation process will gamify those processes,' Press release 12 April 2011. www,.gartner.com/newsroom/id/162914 (accessed 7 February 2014), 2015

[3] Yusuff SA, Oladimeji MS, Ahmodu OL, Adeniyi AB. Gamification on sales force performance in Nigeria Bottling Company. Games Review 2019 4(1)1-8.

[4] Zichermann G, Cunningham C. Gamification by design: Implementing game mechanics in web and mobile apps. O'Reilly Media, Inc. pp172-178

[5] Hanus Michael D, Jesse Fox. Assessing the effects of gamification in the classroom: A longitudinal study on intrinsic motivation, social comparison, satisfaction, effort, and academic performance." Computers and Education 2015, 80: 152-161.

[6] Meister, Jeanne C., and Karie Willyerd. "Mentoring millennials." Harvard Business Review 2010, 88(5): 68 .

[7] Twenge JM. Teaching generation me. Teaching of Psychology 2013, 40(1): 66-69.

[8] BuckleyP, Doyle E. Gamification and student motivation. Interactive learning environments 2016, 24(6): 1162-1175.

[9] Hamari Juho, Kai Huotari, Juha Tolvanen. Gamification and economics. The game ful world: Approaches, issues, applications 2015, 139-162

[10] Hew KF, Huang B, Chu KWS, Chiu DKW. Engaging Asian students through game mechanics: Findings from two experiment studies. Computers \& Education 2016, 92: 221-236.

[11] Mruthyanjaya Rao M, Prasad KDV, Vaidya R. Optimization of Human Resources: Does Human Resource Pooling in an Organization Help in Improving Capacity Building and Efficiency? A Case Study. Journal of Human Resource and Sustainability Studies 209, 7(3): 397-405.

[12] MSG. Management Study Group. Common Resource Pool Model of Human Capital Management,https://www.managementstudyguide.com/common-resource-pool-model-of-humancapital-management.htm2, 2018

[13] Oracle Corporation. Understanding Resource Pools. Oracle Corporation. https://docs.oracle.com/cd/E51433_01/fscm92pbr2/eng/fscm/frmt/concept_UnderstandingResource Pools-9f296d.html, 2016

[14] Deterding S, Khaled R, Nacke L, Dan Dixon. Gamification: Toward a definition. In CHI 2011 gamification workshop proceedings, vol. 12. Vancouver BC, Canada, 2011.

[15] Werbach Kevin, Dan Hunter. For the win: How game thinking can revolutionize your business. Wharton Digital Press, 2012.

[16] Aberdeen Group. It is time to gamify your onboarding program? Research report,Boston, MA, Aberdeen group, 2013

[17] Simpson P, Jenkins P. Gamification and Human Resources: an overview. Brighton: Brighton Business School (2015).

[18] Boer P V. Introduction to Gamification. Piet van den Boer.-29 p (2018).

[19] CIPD. From e-learning to gameful employment., Sustainable organization Performance Research Programme, London: Chartered Institute of Personnel and Development, 2012

[20] CIPD. Learning methods fact sheet, revised, Chartered Institute of Personnel and Development, 2014

[21] Pink Daniel H. Drive: The surprising truth about what motivates us. Penguin, 2011. 
[22] Bunchball, Inc. Gamification 101: An introduction to the use of game dynamics to influence behavior. White paper 9,2010

[23] Kananen J, Akpinar M. Gamification of the sales process at a telecommunications company to improve the motivation of the salesforce., 2015

[24] De-Marcos, Luis, Adrián Domínguez, Joseba Saenz-de-Navarrete, and Carmen Pagés. An empirical study comparing gamification and social networking on e-learning. Computers \& Education 2014, 75: 82-91.

[25] Landers, Richard N., Kristina N. Bauer, and Rachel C. Callan. "Gamification of task performance with leaderboards: A goal setting experiment." Computers in Human Behavior 71 (2017): 508-515.

[26] Savitz E. Let's play: To keep gen Y staffers at work.Forbes, 2012

[27] Krysty Prima,Organizations explore benefits of pooling workers. IT World Canada. https://www.itworldcanada.com/article/organizations-explore-benefits-of-pooling-workers/26353, 2002

[28] Francis Coleman and Gerry Winters, The power of pooling resources. IPE https://www.ipe.com/analysis/analysis/the-power-of-pooling-resources/18528.article, 2006

[29] Msiska, B, Pooling human resources needed to leverage open source health information software platforms in developing countries. 2017 IST-Africa Week Conference (IST-Africa), Windhoek, 2017, pp. 1-8. doi: 10.23919/ISTAFRICA.2017.8102370, 2017

[30] Oasis HR, RTT - Part 1 - Talent Pooling on Paper: Building the Business Case and Measuring ROI. HR Think Tank Series. Resourcing Think Tank. https://oasishr.com/part-1-talent-pooling-paperbuilding-business-case-measuring-roi/, 2014

[31] Reda, James, What You Need to Know About Pooling of Interests Accounting, Journal of Compensation and Benefits,Available at SSRN: https://ssrn.com/abstract=2390286_Review, 1999.

[32] Dr. Govind Dave and Kirti Makwana, A Study on Assessing Expatriate's Challenges during an International Assignment: International Human Resource Management Perspective. International Journal of Marketing and Human Resource Management, 7(2), 2016, pp. 23-35.

[33] Dr. R. Khader Mohideen and A. Sophia Alphonse, A Study on Employees' Perception on Human Resource Management Practices in Cement Industries Special Reference to Madras Cements Limited (Ramco), Ariyalur, International Journal of Management (IJM), Volume 6, Issue 1, January (2015), pp. 594-602.

[34] K.R Jose and Prof. Abhijit Bhirud, Analysis of Factors Affecting Human Resource Management of Construction Firms and Probable Solutions for the Remedy of the Issues: Towards Successful Completion International Journal of Advanced Research in Engineering and Technology, 9(6), 2018, pp19-29

[35] Martina Königová and Hana Urbancová, Evaluation of Factors Influencing Human Resource Branding in the Czech Republic and the Slovak Republic, International Journal of Marketing and Human Resource Management (IJMHRM), Volume 4, Issue 1, January - April (2013).

[36] D. Prasanna Kumar, A. Satish, SS. Asadi, Evaluation of Human Resources Management in Construction Industry Using Analytical Apporoach: A Model Study, International Journal of Mechanical Engineering and Technology 9(2), 2018, pp. 95-104.

[37] George O. Mainoo, Bright Addo and Ennim Bortsie Kobina, Human Resource (HR) Practices and Employee's Job Satisfaction: Focus on a Public Institution in Ghana, International Journal of Marketing and Human Resource Management (IJMHRM), Volume 5, Issue 4, July - August (2014), pp. 06-18. 